\title{
Takayasu Arteritis: A Rare Case Report with Ultrasonographic and Color Doppler Features
}

\author{
SAJID ANSARI, ${ }^{1}$ ABHISHEK KUMAR, ${ }_{1}^{1}$ KANCHAN DHUNGEL, ${ }^{1}$ KALEEM AHMAD,${ }^{1}$ PANNALAL SAH,${ }^{1}$ \\ MUKESH KUMAR GUPTA, ${ }^{1}$ RK RAUNIYAR, ${ }^{1}$ MD FARID AMANULLAH ${ }^{2}$
}

\begin{abstract}
:
Takayasu arteritis is a rare form of large vessel vasculitis predominantly occurs in young females. Ultrasonography is usually the primary modality of investigation in a patient with signs and symptoms of Takayasu arteritis and features includes wall thickening, luminal narrowing or stenosis, occlusion, luminal dilatation and aneurysms and high resistance flow patterns. Suppression of inflammation and preservation of vascular competence are the aims of treatment. We present the sonographicand color Doppler findings of Takayasu arteritis in a 21 year old female.
\end{abstract}

Keywords:Takayasu Arteritis, Aortoarteritis, Sonography, Color Doppler, Macaroni sign.

\section{Introduction:}

Takayasu's arteritis is a rare large vessel vasculitis affecting the aorta and its major branches, typically occurring in young individuals. ${ }^{1}$ It is also known as pulseless disease, Martorell syndrome, aortic arch syndrome or atypical coarctation of the aorta. ${ }^{2,3}$ The incidence of this disease is higher in Asian countries, Mexico and the United States. ${ }^{3,4}$ The age of first appearance varies from 3 to 48 years. Conventional angiography is considered as the gold standard for the diagnosis. Multiple imaging modalities like CT, MRI and PET are available; however high-resolution ultrasonography is a useful, noninvasive tool for the assessment of arterial involvement. ${ }^{5}$

\section{Case Presentation:}

A 21 year old female presented with complaints of pain and tingling sensation in both upper limbs, more on the left. There was past history of mild exertional dyspnea and dizziness 9 months back. On clinical examination, she was afebrile, heart rate was $86 \mathrm{bpm}$. Blood pressure was 160/62 $\mathrm{mmHg}$ in the right arm, 74/50 mmHg in the left arm, 130/60 $\mathrm{mmHg}$ in the right leg, and $122 / 60 \mathrm{mmHg}$ in the left leg. Bruits were noted over both carotid and subclavian arteries and over the abdomen. The left radial pulse was feeble. Cardiovascular and respiratory evaluation was within normal range and abdomen was soft and non-

1. Department of Radiodiagnosis, B.P. Koirala Institute of Health Sciences, Dharan, Nepal,

2. Department of Orthopaedics, B.P. Koirala Institute of Health Sciences, Dharan, Nepal.

Correspondence : Dr..Sajid Ansari, MD (Radiodiagnosis and Imaging),Department of Radiodiagnosis, B.P. Koirala Institute of Health Sciences, Dharan, Nepal. Address: H-2733, BPKIHS, Dharan, Nepal. Email address: drsajidansari@yahoo.co.in
tender.Laboratory tests revealed mild anemia (hemoglobin $11.2 \mathrm{~g} / \mathrm{dL})$, and elevated inflammatory markers: ESR $(80 \mathrm{~mm} /$ h) and CRP (5.1 mg/dL).

Sonography along with color Dopplerwas done with 5-12 $\mathrm{MHz}$ frequency transducer which revealed long segment, diffuse, homogenous circumferential wall thickening (Figure 1,2 and 3a) along with luminal narrowing of bilateral subclavian, common carotid, axillary, radial and ulnar arteries with high resistance flow pattern on spectral tracing (Figure 3b).Narrowing of abdominal aorta distal to the celiac axis was also noted (Figure 5). After clinical, laboratory and sonographic correlation, she was diagnosed as Takayasu arteritis and oral prednisone and methotrexate was started. On follow-up sonography there was decrease in the wall thickness of the involved vessels.

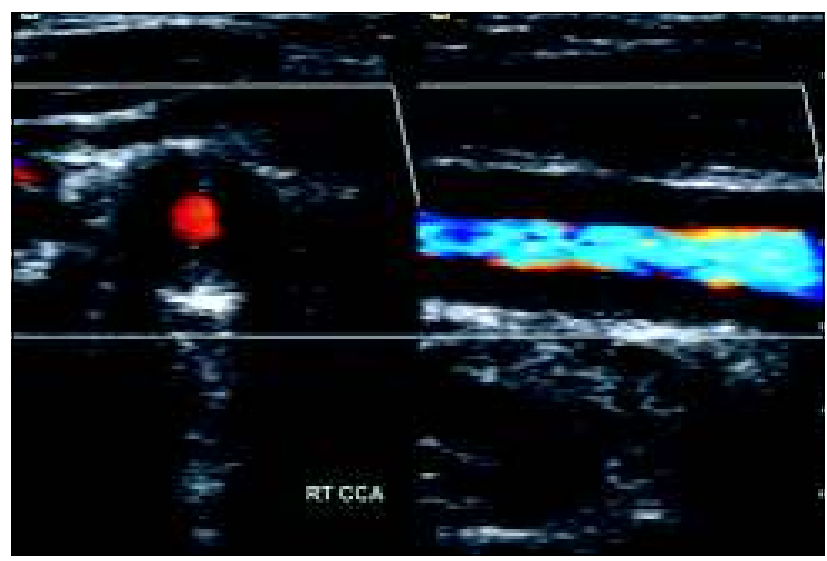

Fig.-1:Transverse and longitudinal sonographic imagesshowing diffuse wall thickening and luminal narrowing of right common carotid artery (CCA). 


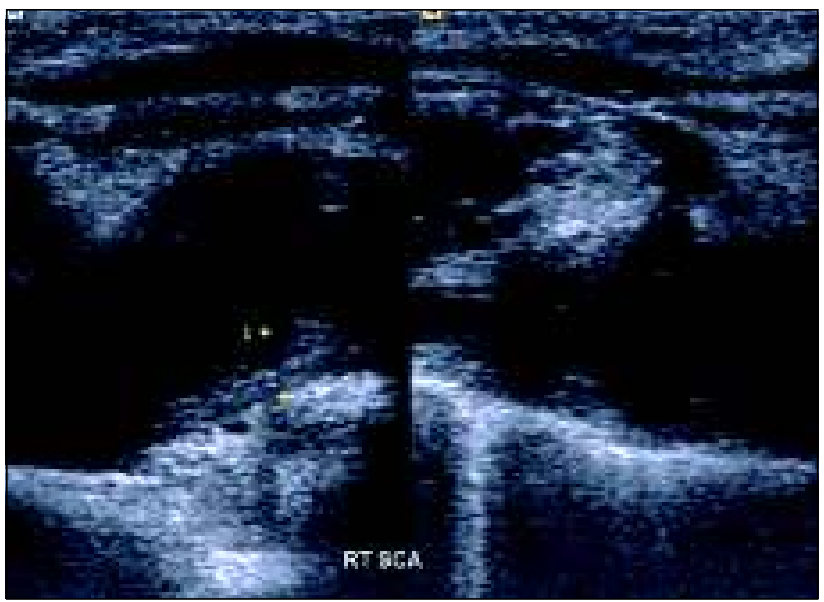

Fig.-2:Transversesonographic image showing diffuse wall thickening of right subclavian artery (SCA) with luminal dilatation due to distal narrowing.

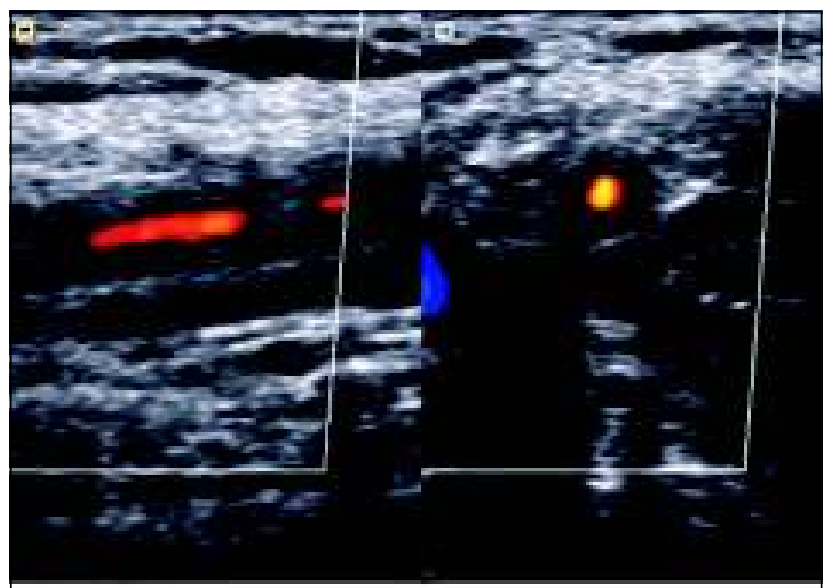

(3a)

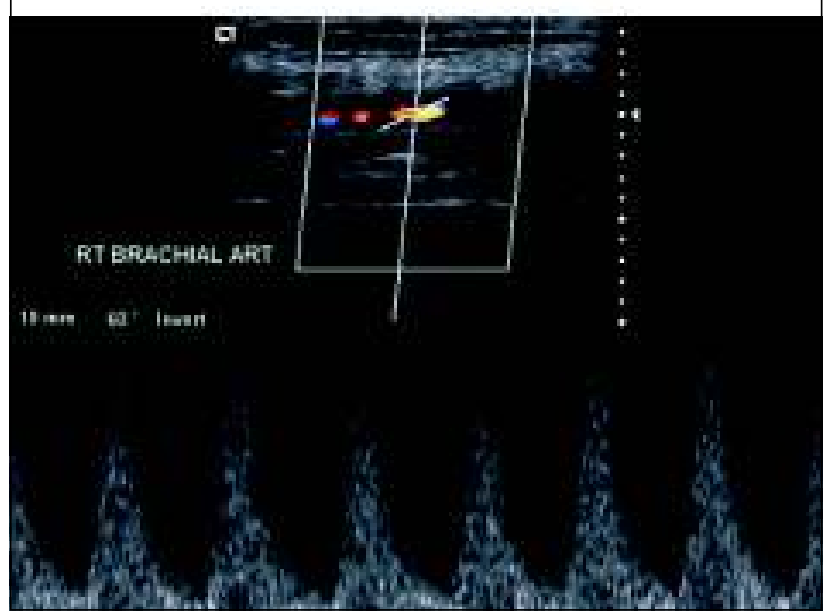

(3b)

Fig.-3a and 3b:Transverse and longitudinal sonographic images(Figure 3a) showing diffuse wall thickening and luminal narrowing of right brachial artery with high velocity flow on color Doppler (Figure 3b).

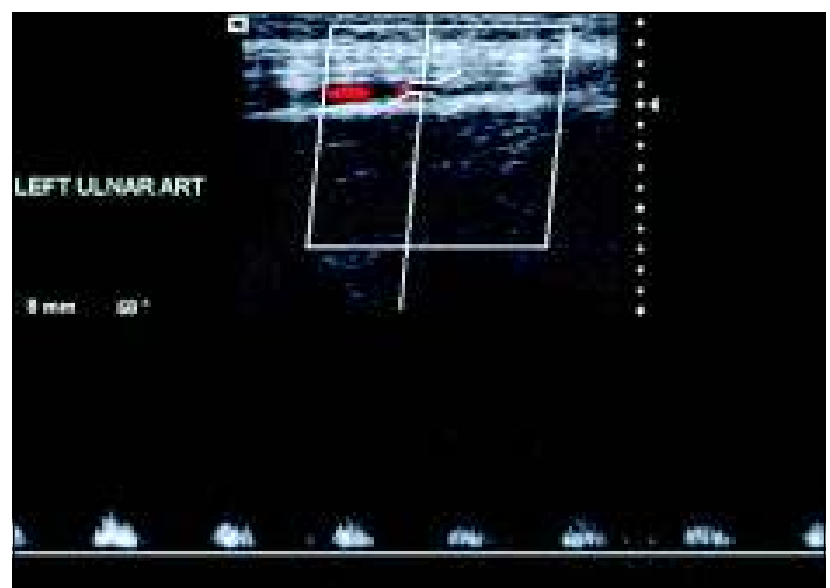

Fig.-4:Doppler sonographicimage showing loss of triphasicity with monophasic low flow pattern in the left ulnar artery due to proximal brachial artery narrowing.

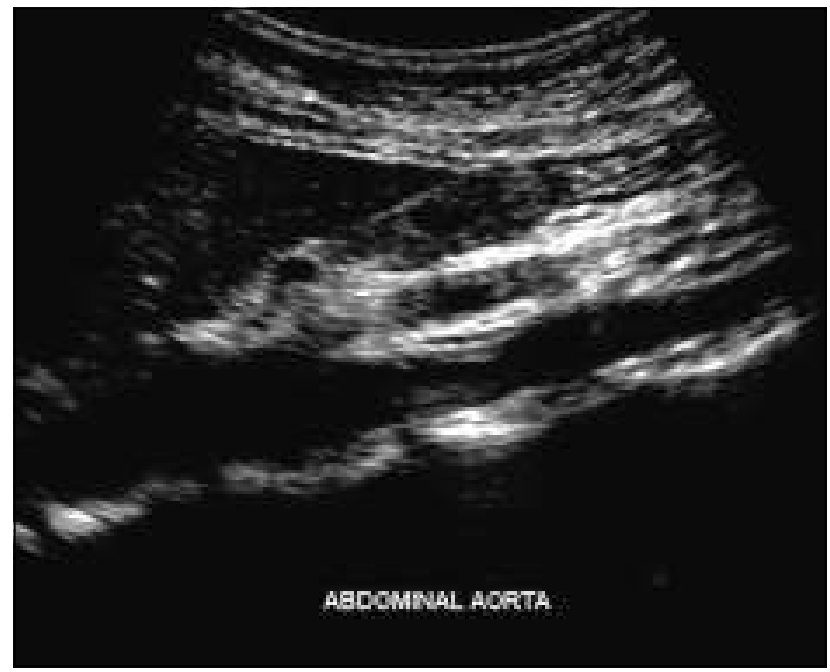

Fig.-5: Longitudinal sonographic image showing luminal narrowing of abdominal aorta distal to celiac axis.

\section{Discussion:}

Takayasu arteritis is a rare inflammatory granulomatous vascular disease. Three phases has been mentioned; early prepulseless phase characterized by systemic symptoms like malaise, low-grade fever, weight loss and arthralgia. It is followed by the phase of active vascular inflammation and in advance phase, fibrotic and stenotic lesions characterize the so-called burnout disease are seen. Neurological features occurs secondary to hypertension and/or ischaemia, including postural dizziness, seizures, and amaurosis.

Sonographic signs include wall thickening, luminal narrowing or stenosis, luminal occlusion, luminal dilatation and aneurysms,calcification and high resistance signals in typically low resistance vascular beds. Wall thickening is the earliest finding with frequent involvement of arch of 
aorta and its major branches. The most frequently involved arteries are subclavian (90\%), carotid (45\%), vertebral (25\%) and renal $(20 \%)$ arteries. ${ }^{1}$ In Takayasu arteritis, long segments of diffuse, homogeneous, circumferential vessel wall thickening are seen. This finding is more common incommon carotid artery in Takayasu arteritis and has been described as the "Macaroni sign".6,7,14 It can be distinguished from arteriosclerosis, which is more inhomogeneous. ${ }^{7,8}$

Increase in wall thickness causes decreased pulsatility and loss of normal triphasic flow patternwith monophasic (Figure 4) or biphasic parvustardus type of spectral flow pattern. The diagnosis is often delayed until arterial fibrosis and stenosis occurs. ${ }^{13}$ The radiographic findings are a result of adventitial thickening, inflammation and cellular infiltration of the tunica media and intimal hyperplasia. ${ }^{14}$ Aneurysm formation occurs due to significant destruction of the tunica media. There is long segment luminal stenosis or narrowing as compared with atherosclerosis or fibromuscular dysplasia, in which the stenoses are usually short segments. Calcification is more commonly seen in atherosclerosis. Lumen occlusion is found in the advance phase. Due to chronicity and slow progression of the disease, occlusions are commonly associated with collateral flow. ${ }^{8}$

Complications in Takayasu arteritis are retinopathy, secondary hypertension, aortic regurgitation, and aneurysm formation. ${ }^{5}$ The pulmonary trunk is found to be more commonly involved compared with the intrapulmonary arteries. ${ }^{9}$ Retroperitoneal fibrosis with or without mediastinal fibrosis, periaortic fibrosis, nephrotic syndrome, glomerulonephritis, ulcerative colitis and crohn disease has also been described by several researchers. ${ }^{11-13}$

Steroid and methotrexate therapy are the main medical treatment for Takayasu arteritis; however mycophenolatemofetil may be useful. Surgery is indicated in severe renal artery stenosis, extremity claudication limiting daily activities, cerebrovascular ischaemia, moderate aortic regurgitation and cardiac ischaemia. Takayasu arteritis is a systemic vasculopathy that can progress to cause vital organ ischaemia, hence long term follow up is recommended.

\section{Conclusion:}

Sonography is often the primary modality of investigation in a patient with signs and symptoms of Takayasu arteritis. Sonography in conjunction with color Doppler scanning is a valuable tool for accurate diagnosis, grading, follow-up and response to treatment.

\section{Conflict of Interest : None}

\section{References:}

1. Mason JC. Takayasu arteritis - advances in diagnosis and management. Nat Rev Rheumatol. 2010; 6(7):406-415.

2. Eagle KA, De SanctisRW. Diseases of the aorta. In: Braunwald E (ed). Heart Disease: A Textbook of Cardiovascular Medicine. $4^{\text {th }}$ ed. Philadelphia, PA: WB Saunders Co; 1992:1528-1553.

3. Lupi-Herrera E, Sanchez-Torres C, Marcushamer J, et al. Takayasu'sarteritis:clinical study of 107 cases. Am Heart J 1977; 103:93-94.

4. ShelmarJH, Volkman DJ, Parrillo JE, et al. Takayasu's arteritis. Ann Intern Med 1994; 120:919-929.

5. Pipitone N, Versari A, Salvarani C. Role of imaging studies in the diagnosis and follow-up of large-vessel vasculitis: an update. Rheumatology (Oxford). 2008; 47(4):403-408.

6. Kerr G. Takayasu's arteritis. CurrOpinRheumatol 1994; 6:3238.

7. Maeda H, Handa N, Matsumoto M, et al. Carotid lesions detected by B-mode Ultrasonography in Takayasu's arteritis: "macaroni sign" as an indicator of the disease. Ultrasound Med Biol 1991; 17:695-701.

8. Sharma S, Rajani M. Aortic occlusion in nonspecific aortoarteritis (Takayasu disease): incidence and spectrum of involvement. AustralasRadiol 1993; 37:57-59.

9. Lupi-Herrera E, Sanchez-Torres G, Horwitz S. Gutierrez FE. Pulmonary artery involvement in Takayasu's arteritis. Chest. 1975; 67:69-74.

10. Lance NJ, Levinson DJ. Aortitis and periaortic fibrosis. J Rheumatol 1991; 18:1095-1097.

11. Hellmann DB, Hardy K, Lindenfeld S, Ring E. Takayasu's arteritis associated with crescentric glomerulonephritis. Arthritis Rheum 1987; 30: 451-452.

12. AcharKN, Al-Nakib B. Takayasu's arteritis and ulcerative colitis. Am J Gastroenterol 1986; 81:1215-1217.

13. Andrews J, Mason JC. Takayasu's arteritis—recent advances in imaging offer promise. Rheumatology (Oxford). 2007; 46(1):6-15.

14. Chaubal N, Dighe M, Shah M. Sonographic and color doppler findings in aortoarteritis (Takayasu arteritis). J Ultrasound Med. 2004; 23(7): 937-944. 